Meta

Journal des traducteurs

Translators' Journal

\title{
Working into the B Language: The Condoned Taboo?
}

\section{Hyang-Ok Lim}

Volume 50, numéro 4, décembre 2005

Pour une traductologie proactive - Actes

For a Proactive Translatology — Proceedings

Por una traductología proactiva - Actas

URI : https://id.erudit.org/iderudit/019870ar

DOI : https://doi.org/10.7202/019870ar

Aller au sommaire du numéro

Éditeur(s)

Les Presses de l'Université de Montréal

ISSN

0026-0452 (imprimé)

1492-1421 (numérique)

Découvrir la revue

Citer cet article

Lim, H.-O. (2005). Working into the B Language: The Condoned Taboo? Meta, 50(4). https://doi.org/10.7202/019870ar

\section{Résumé de l'article}

Une enquête a été réalisée en 2003 au près des interprètes coréen-anglais résidant en Corée. Il s'agissait de savoir ce que ces professionnels pensent de l'interprétation en langue $\mathrm{B}$, activité bien répandue et acceptée dans certains pays, un taboo dans d'autres. Une autre enquête similaire a été réalisée auprès d'interprètes de conférence membres de l'AIIC. Dans cet article, nous tentons de comparer les résultats de ces deux enquêtes afin de voir si les interprètes partagent les mêmes opinions vis-à-vis de l'interprètation en B ou si leur points de vue se divergent sur ce sujet épineux.
Ce document est protégé par la loi sur le droit d'auteur. L'utilisation des services d'Érudit (y compris la reproduction) est assujettie à sa politique d'utilisation que vous pouvez consulter en ligne.

https://apropos.erudit.org/fr/usagers/politique-dutilisation/ 


\title{
Working into the B Language: The Condoned Taboo?
}

\author{
HYANG-OK LIM \\ Hankuk University of Foreign Studies, Seoul, Korea \\ hyangoklim@hanmail.net
}

\begin{abstract}
RÉSUMÉ
Une enquête a été réalisée en 2003 au près des interprètes coréen-anglais résidant en Corée. Il s'agissait de savoir ce que ces professionnels pensent de l'interprétation en langue B, activité bien répandue et acceptée dans certains pays, un taboo dans d'autres. Une autre enquête similaire a été réalisée auprès d'interprètes de conférence membres de l'AIIC. Dans cet article, nous tentons de comparer les résultats de ces deux enquêtes afin de voir si les interprètes partagent les mêmes opinions vis-à-vis de l'interprètation en B ou si leur points de vue se divergent sur ce sujet épineux.
\end{abstract}

\begin{abstract}
A survey was conducted in 2003 among Korean-English interpreters residing in Korea to study their views regarding interpreting into B - something that is considered the norm in some countries, while almost taboo in other countries. Following the first survey, a second similar survey was conducted among AIIC members across the world. This compares the two surveys in an attempt to determine whether the sentiment about interpreting into B is different among interpreters regardless of their language combination - or whether it is relatively the same.
\end{abstract}

\section{MOTS-CLÉS/KEYWORDS}

interpreting into B, consecutive interpretation, simultaneous interpretation, language combination, Korea

\section{Introduction}

Though the AIIC website defines the B language as "A language other than the interpreter's native language, of which she or he has a perfect command and into which she or he works from one or more of her or his other languages. Some interpreters [work] into a "B" language in only one of the two modes of interpretation." "(AIIC website; emphasis added), the general understanding among interpreters around the world is that one should preferably work only into one's 'A' language or mother tongue. In fact, the AIIC Professional Standards do not spell out in so many words that interpreters should or must work only into their A language nor does it mention anything about directionality. The only indirect indication can be found in Article 6 of the Professional Standards which stipulates the number of interpreters needed in different configurations with varying language combinations, but it does not mention that interpreters should only work into their A language. The Professional Standards and Code of Professional Ethics simply mention that relay should be avoided whenever possible. Article 7(a) of the Code of Professional Ethics states that the members "shall try to ensure that teams of conference interpreters are formed in such a way as to avoid the systematic use of relay." Article 6(3) of the Professional Standards states that "Teams of interpreters must be put together in such a way as to avoid the systematic use of relay. However, when there is no alternative to the use of relay for a given language, the team shall comprise at least two interpreters able to provide a relay from that language. In addition, if the relay is provided from a two-way booth, at least three interpreters shall work in that booth." Among most Western European languages, working into one's B language and relay can be avoided without much difficulty. However, with more exotic languages or less widely diffused languages such Korean or Hungarian, working into one's B language and relay are unavoidable. Even for Chinese and Arabic which are official UN languages, interpreters must and do work into their B, thereby providing relay for the other interpreters. One of the major problems that the EU faces as it expands and accepts 
more members into its fold is, in fact, the problem of communication, since members are supposed to be able to speak in their mother tongue. Even the EU cannot but consider relay and remote intepretation as well as videoconferencing and teleconfereing as alternatives to conventional SI - for personnel reasons since there simply are not many interpreters who can, for example, work from Estonian, Lithuanian or Hungarian into French or English as their mother tongue, as well as for budgetary reasons.

Various scholars have discussed the problems and pitfalls of interpreting into B.

Seleskovitch \& Lederer (1989) outlined three points that they felt supported their argument that simultaneous should be taught mainly into the mother tongue. They felt that working into B added an extra element of stress to an already stressful situation and therefore should be avoided at all costs in order to ensure quality interpretation.

Simultaneous interpretation imposes stressful working conditions and is already arduous enough. All unnecessary difficulties should be eliminated. Having the students work into their own language enables them to concentrate on what is important...second, working into the native tongue, that is, one which comes intuitively, yields natural-sounding languages which native speakers can follow easily; and third, working into the native language relieves the interpreter from consciously having to search for idiomatic expressions in the foreign language and getting behind. It automatically assures that the interpretation will be complete and the whole content conveyed (p.113-114).

Perhaps the picture being drawn in this case is an ideal that does not always reflect reality. If the main purpose for working into the native tongue is so that native speakers can follow easily, then this is most certainly not the case in many interpretation situations. In Korea, more often than not, the speaker as well as the recipients are non-native speakers of English who are grateful that they can understand what has been said in Korean.

The main concern is that students, and later interpreters, will not be able to provide quality interpretation when working into their B language because they struggle and have to make an extra effort in order to work in that direction. In fact, for reasons of quality, Seleskovitch (1999) has long held that simultaneous interpreting into a ' $\mathrm{B}$ ' language should be avoided at all costs.

The underlying assumption of many of those who advocate interpreting into ' $\mathrm{B}$ ' is again that interpreting is tantamount to substituting target language words for source language words... When listening to actual interpretation, however, the superiority of an 'A' language over a ' $\mathrm{B}$ ' language is obvious. Few interpreters working into and from widely used languages have a good enough working knowledge of their $\mathrm{B}$ languages to be able to perform equally well into both their ' $\mathrm{B}$ ' and 'A' languages...The enlargement of the European Union to include Central and Eastern European countries will undoubtedly result in an increased demand for interpretation into B from less widely known languages. Schools will therefore no doubt introduce in their curricula training into B in simultaneous.

Seleskovitch criticized those who condone interpreting into B, mainly because she believed that the discrepancy in the output was too great to be acceptable, but nevertheless recognized the fact that it is an unavoidable trend. However, just because one advocates interpreting into ' $\mathrm{B}$ ' does not mean that one naturally assumes that "interpreting is tantamount to substituting target language words for source language words." Even while defending the théorie du sens, it is possible to believe that interpreting into B is feasible, acceptable and should be part of the curriculum of any school of interpretation.

Dejean LeFéal (2000), also of the Paris school, believes that there is an insurmountable difference between the active and passive language and explains the difference in the following manner:

In an acquired language we do not have the support of instinct - the basic sense of language which guides us and dictates, as if by magic, the most appropriate way of expressing our thoughts. This instinct is not just creative; it is also "corrective" in the sense that it alerts us to every defect of form. When one is speaking in one's native tongue and when one has, for whatever reason, constructed a sentence poorly, one 
immediately feels ill at ease at having expressed oneself incorrectly or awkwardly. When mentally going over the incorrect sentence, one immediately discovers the imperfection and one is then able to correct it without going through a grammatical analysis. (p. 11)

Having taught the régime special at ESIT which consists of teaching students whose mother tongue is not an official language of the ESIT, Dejean LeFéal has numerous years of experience with students working into their B language. By listening to the output only, she could determine whether or not the interpretation was accurate and faithful to the original speech. In explaining the difference between an active and passive language, she focuses on the instinctive reaction that one has with one's mother tongue, so that if a mistake is made, it will be automatically corrected.

Newmark (1981) also makes the clear distinction between native and non-native and is adamant that working into one's non-native is not feasible, but he seems to leave it to the conscience of the interpreter or translator when he says

The translator is in the best position to appreciate the 'total' difference between one language and another. He himself usually knows that he cannot write more than a few complex sentences in a foreign language without writing something unnatural and non-native, any more than he can speak one. He will be 'caught' every time, not by his grammar, which is probably suspiciously 'better' than an educated native's, not by his vocabulary, which may well be wider, but by his unacceptable or improbably collocations." (p.180)

Donovan, also a proponent of the Paris interpretive theory of translation, indicates that "care is needed to ensure that SI into B does not become systematic regardless of proficiency in the $\mathrm{B}$ language, the risk being that all interpreters with relevant language combinations will come to feel obliged to work into B - or indeed bullied into doing so - to enhance their "market value." but concededs that "SI into B is needed, but training and selection are of the essence, as interpreters or trainee interpreters must have robust interpreting skills and B language proficiency" (Donovan 2003: 369). ${ }^{2}$

Pöchhacker (2004) describes the parameters of SI and compares them with sign language.

The western tradition of conference interpreting has favored simultaneous interpreting from B- or Clanguages into an interpreter's A-language. A-to-B interpreting, or retour interpreting, though widely practiced on the 'local', or private market, has not been equally accepted for simultaneous interpreting in international organizations. In contrast, sign simultaneous interpreting as A-to-B interpreting and consider B-to A-, that is, sign-to-voice interpreting, the more challenging direction. (p.21)

The fact that SI into B was not equally accepted at international organizations was simply because there was no need to work into B since there was always someone who could work in that language combination while working into A. Since that is no longer the case, especially with the expansion of the EU, it will probably no longer be so unusual to find interpreters working into B. Baker (1992), again, was not so optimistic about working into the B language because the 'feel' that one has for one's native tongue can not be duplicated and she stated blatantly that

A person's competence in actively using the idioms and fixed expressions of a foreign language hardly ever matches that of a native speaker. The majority of translators working into a foreign language cannot hope to achieve the same sensitivity that native speakers seem to have for judging when and how an idiom can be manipulated. (p. 64)

She continues by quoting the Code of Professional Ethics of the Translators' Guild of Great Britain which stipulates that a translator should only work into the language of which he has native knowledge. Only in exceptional cases is working into a B language accepted.

Dollerup (1996), however, suggests the use of bidirectionality as a pedagogical tool and finds some positive aspects about working in both directions. 
Single directionality makes it possible to use translation exclusively as an instrument for foreign language acquisition, for instance as grammar drills, and not as an activity distinct from language acquisition.

Conversely, double directionality brings to light a number of factors in the translation activity which were ignored in single-directionality classes, such as the opaqueness of source texts and the importance of fluency and style in target texts. (p.27)

Setton (1994) who taught interpretation in Taiwan and therefore is knowledgeable about the Asian market, explained the inevitability of working into B as well as relay, in some areas of the world.

The market requires interpreters to be fully 'bi-active', i.e. able to work accurately and produce acceptable grammar, vocabulary, register, etc. in two languages, both in consecutive and simultaneous. Also, since most multilingual conferences require Chinese, English and Japanese, relay interpreting (in which interpreters have to rely on a colleague's version from source languages they do not themselves understand) is the rule, not the exception, placing high demands on production of the acquired language, particularly in terms of clariy, compression and cohesion. (pp.185-186)

Relay is an issue that is closely related to working into B. At multilingual conferences in Asia, it is not unusual to have to resort to relay to cover all the language combinations. ${ }^{3}$

Minns (2002) who also taught students at ESIT who worked into their B language, indicated that we must "cater for what is increasingly a definite need." He outlined nine techniques that he uses when teaching interpretation into B as opposed to those who have English as a mother tongue, some of which include purely linguistic instruction. While recognizing that the increasing number of multilingual conferences around the world and the EU enlargement will require more interpreters to work into $\mathrm{B}$, he nevertheless emphasizes that

The qualities required of an interpreter in these languge combinations are no different than for any other, which means that the teaching of interpreting into B has to take place in a full and balanced course of conference interpreting, requirring the same selection and teaching criteria that have been tried and tested in well established schools of interpreting over the years. What is more, the teaching of interpreting into B, particularly in simultaneous should be started only if the student can already provide a satisfactory interpretation into the A language and has clearly mastered the basic techniques of consecutive and simultaneous. (pp.38-39)

Perhaps a sub-conclusion that could be reached upon this literature review would be to say that ideally, interpreters should not work into their B language and when possible, avoid doing so. However, since the world is not the ideal place that is dreamed about in academia, it might be more realistic to include interpretation into B (both consecutive and simultaneous) in the curriculum for the lesser used languages, making sure that great care is taken to ensure that it is an incremental process and that the students have grasped the intricacies of interpretation from B into A.

\section{The First Survey ${ }^{4}$}

The target population of the first survey was 45 active Korean-English interpreters residing in Korea. ${ }^{5}$ The response rate of this survey that was conducted in the summer of 2003 was $46.6 \%$ With regard to directionality, more than half of the respondents, $57 \%$, said that they were equally comfortable working into Korean as they were working into English, though two respondents did mention that it depended on the topic. The general indifference that the interpreters showed regarding directionality is probably due to the fact that if an interpreter were fastidious about working only into Korean, the A language for all the interpreters, it would probably be relatively more difficult to find work and they might consider it to be a sign that they are less competent than those who can work bi-directionally. Organizers would have to take into consideration when forming teams that, for example, Interpreter $\mathrm{X}$ will work only into Korean, meaning that her partner would have to take the load of working into B, while in most cases, unless there is an understanding 
between the interpreters themselves, the workload, including direction, is equally divided. Since the interpreting world in Korea is even smaller than in Europe, interpreters know each other, either directly or indirectly, and consequently know each other's strengths and weaknesses. If there is any adjustment that needs to be made, the interpreters will usually do so among themselves.

Those who answered that they were more comfortable working into English mentioned that foreigners are more forgiving, easy to please; some answered that it was difficult to understand nonnative English speakers, and that therefore the other direction was easier. Predictably, those interpreters who preferred to work into Korean, did so because they felt that they could manipulate the language better. In crisis situations, the interpreters thought that they could twist and turn, and ultimately land on their feet when working into their mother tongue. This supports the argument that interpreters should work only into their native language because they have the flexibility that is needed.

Those respondents who made the distinction between interpretation modes answered that they would work into English in consecutive but not simultaneous. This is understandable since in consecutive, the interpreter can work at her own pace.

In the additional comments, one interpreter said that the direction is not a primary concern, but rather that the subject and familiarity with the subject was a greater concern. All interpreters have probably, at one time or another, been in a situation in which they could understand all the words but did not understand the ideas or concepts behind them and therefore were unable to interpret or struggled to do so. Once the message has been grasped, professional interpreters are able to convey the message - a little more stylishly into the mother tongue, and perhaps a little more roughly into B - but nevertheless comprehensibly to the recipient of the message.

Among the additional general comments, one comment was particularly telling. The interpreter stated that to be considered worth one's salt, a true interpreter should be able to work equally into both languages and not be constrained by the direction in which one works. This is in stark contrast with Western AIIC interpreters who consider it an exception to work into their B language and probably do not consider such a request to be the norm. This is not to state that one way is better or should be considered the norm over the other. It is simply to note that there is a big difference in what the market demands and how the interpreters themselves perceive the demands. While Western interpreters are required to have several B's or C's and work mainly into their A language, Asian interpreters work bi-directionally but usually have only two languages.

If this is the reality that interpreters face, it goes without saying that schools of interpretation and translation need to take this into account when designing curriculum. For example, most educational institutions in the West do not teach simultaneous interpretation into B, while most schools in Korea have the same number of classes in both directions (Lim, 2001). Teaching interpretation into B involves a different mindset. While a large portion of instruction into A might be spent on tracing what the students did not understand or misunderstood, that is the listening and understanding portion of the process, instruction into B is oftentimes more focused on reproduction or the end product. This means that the classes, at first glance, can sometimes resemble language classes because comments might be made about grammar, pronunciation, terminology and unclear ideas. However, the instructor and students should be constantly aware that unlike language classes, the comments made about grammar are not comments about the grammar per se, but rather comments about the grammar as it pertains to the message. In other words, objectively speaking, sometimes the grammar might be correct, but with regards to the original message, it could be wrong. The same is true for pronunciation, terminology and unclear ideas. They should always be in relation to the message. Donovan (1998) states that "when correcting, teachers must be careful not to create the impression that they are criticizing specific word translations, as this merely reinforces the students' erroneous methodology of attempting to transpose languages. Rather the teacher must query unclear, disconnected expression, because it is at odds with the speaker and the situation." 


\section{The Second Survey}

The second survey was sent out to 1,958 members of AIIC in January of this year; out of which $1,056(54 \%)$ remained unread; $791(40 \%)$ were returned and $111(6 \%)$ were answered. Among the replies were included 77 full responses to the questionnaire; $9(12 \%)$ were automatic responses that they were unable to answer the e-mail because they were out of country; $21(27 \%)$ answered that they could not answer because they did not have a B; one (1\%) said that he/she no longer worked; and $6(8 \%)$ were incomplete. The response rate was very low and insufficient to reach any definite conclusions. Nevertheless the responses could appear to reflect the situation among AIIC members.

Almost half of the respondents had been members of AIIC for more than ten years; added together with those that had been members for 5-10 years, a total of 70\% of the respondents have worked for more than five years which means that they have enough experience to be able to accurately judge the situation.

The language combinations of the respondents were as varied as the number of respondents. The largest number of respondents had French as their A as well as in their combination, but if one does not consider the A language, then the largest number of respondents had English as their B or C - a natural corollary since English is so dominant in international conferences.

Regarding the proportion of consecutive and simultaneous interpretation, $89 \%$ said that less than $30 \%$ of their work was consecutive; while $82 \%$ said that anywhere between $71-100 \%$ of their work was simultaneous, with $45 \%$ saying that $91-100 \%$ of their work was simultaneous. Though not scientifically verified, this can be considered from various perspectives: the increased number of languages at international conferences makes consecutive interpretation impossible; the facilities are easily available; and conference participants are becoming more impatient and do not want to wait for the consecutive.

Coming to the question of directionality, $46 \%$ of the respondents answered that $61-90 \%$ of their work was from C or B into A, and only 9\% said that it was almost all (91-100\%) into A. $22 \%$ of the respondents said that only $10 \%$ of their work was into B; $17 \%$ said $20 \%$ was and only $16 \%$ said that about $30 \%$ of their work was into B. In other words, more than half or $55 \%$ answered that only up to $30 \%$ of their work was into B.

The question was also asked whether the respondents worked into C. About $96 \%$ answered $0-10 \%$, there was one respondent who was extremely indignant that he/she was being asked that question and felt the need to further add, "I'm a professional!" However there were three respondents who answered that, respectively, up to $20 \%, 30 \%$ and even $40 \%$ of their work was into C. One respondent further added that he/she had passed the institution's exam for C interpretation. This was a slightly surprising response because the target population consisted of AIIC members and the language classification of AIIC stipulates that the C language is "The language(s) of which the interpreter has a complete understanding and from which she or he works. Interpreters often have several C languages." (AIIC website) It is generally understood that one does not work into C and the three interpreters who do should probably ask for a reclassification of their languages so as not to cause confusion.

Question 5 asked whether they felt more comfortable working into A or into B in order to determine whether the argument that working into B was acceptable and preferable because there is a better understanding of one's A language. However, $68 \%$ of the respondents said that they 
preferred to work into A; only $8 \%$ said they preferred working into B and $25 \%$ said that it did not matter.

Question 6 asked the reason why they felt more comfortable working into B. 55\% of the respondents answered that in fact it was because they could understand their A language better; and $18 \%$ felt that they could make a better impression on their audience with a fluent B. It is interesting to note that the argument for working into B and the response for working into B actually coincide. Those who answered that they felt more comfortable working into A said that the reason was that they could manipulate the A better since it is the mother tongue (56\%); $26 \%$ said that their understanding of B was greater than their ability to express themselves in B. These respondents are adherents to the Paris school of thought, whether they know it or not. $75 \%$ said that the mode of interpretation - consecutive or simultaneous - did not affect whether or not they would work into B. For those who answered that the mode did affect whether or not they would work into B, the overwhelming majority, $84 \%$, predictably said that they preferred not to work in simultaneous.

Regarding the general feeling about working into B, 44\% said that it was a fact of life and that it should be accepted (this was further emphasized in the additional comments); $24 \%$ said that they could not understand the fuss since some languages, like Arabic, had been doing it from the start; and there were also additional comments. The additional comments for question 9 and the entire survey more or less overlapped, and it was felt that they could be analyzed all together. The results are summarized in the following table:

\section{Category: Survival/Fact of life}

"There is a great demand for work from French into English - which puts English native interpreters in a comfortable position - and if one wants to survive, one must be able to work into English - as it happens, my B language. You can't survive otherwise for the French (national language) -English combination. The bilingual market is the largest. When I can, I like to work with an English A and try to share the work so that we work preferably into our mother tongues. Not always possible. Although my B language is not bad, it hasn't got the depth and elegance of my A language." (FR-ENPT)

"I am convinced that a better quality can always be achieved by having interpreters work into their A language. The imperatives of the market make this impossible however, so working from A into B is acceptable. In most cases C into B must remain the exception. Of course there are many colleagues, above all some with only one A and one B, who do a very good job in both directions." (EN-DE-FR)

"It's a realistic part of interpretation in certain situations." (SV-EN-FR)

"According to me it is different if you work in a bilingual conference (A into B 
and $\mathrm{B}$ into $\mathrm{A}$ ) or in a multilingual context $\mathrm{C}$ into $\mathrm{B}$. Personally I do no interpretation from Spanish into Italian maybe because Spanish is the last language I added and since these are two languages very similar and for this reason very difficult to translate. With my other C (English) I have no problem to work into B but I feel better in English into French, but this is a fact of my life." (FR-IT-EN/ES)

"In some circumstances there is really no choice...you are it. On the US freelance conference market, most of the work is into French (and the English booth rarely works). It makes a lot of sense to have a French A working 10-15\% (maximum) of the time into B, than hire an English A to interpret those 10-15\%, then have to work $35-40 \%$ into his/her B language (French)." (FR-EN/ES)

\section{Category: Subject/Language/Region Specific}

"I must say I feel more comfortable working into Portuguese (A) when topics being discussed are too abstract in nature..." (PT-EN-ES)

"I have no problem working into B French or English, but it may also depend on the subject. There are subjects I love to do into French and less into English. If the subject is very difficult, like medicine e.g., I would prefer to do it in my A, i.e. Hungarian. Finally, there are subjects that I do not accept to do at all, e.g. astrology, chemistry, mathematics etc. You will never be able to translate correctly something you do not understand into your own "A" language." (HU-FR/EN-ES)

"I'm sure it depends on the language. For me, working into my English B can have advantages. On the market that I work in (freelance in Germany) there is a great demand for work into English which cannot possibly be covered by the few native speakers resident in Germany. However, I feel that the quality of English Bs varies greatly. Also, it very much depends on the topic: a very technical conference is not so much of a problem even for a weak B with a good technical vocabulary and technical understanding, whereas a philosophical conference or anything where a more sophisticated language level is required should only be covered by an A or an excellent B." (DE-EN)

"I think different markets work differently. I live in the US and work into my A more than B. However, as far as I know, my colleagues in Taiwan and Mainland China work more into B than I do." (ZH-EN)

\section{Category: Evaluation/Quality}

“There are interpreters with very strong Bs and others who aren't as good. Interpreters should be able to evaluate their skills in a realistic way and judge whether it's a good idea for them to work into B or not. It also depends a lot on the subject and 
whether you know the people and the subject well or not." (DE-EN-FR)

"Yes, it's a fact of life but I generally believe that only those who are able to provide quality interpretation service in a B-language should work in that language and that those who are incapable of doing so should refrain." (EN-FR)

"If your B language is as fluent as you're A language...there should be no problem, provided you do not mind interpreting into that language..." (ES-EN-DE)

"Working into B is all right if your B is good enough." (DE-EN)

When you work in Denmark between English and Danish, as I do, you have to work both ways, because most Danes understand English quite well, so the customers very often won't pay for interpretation into Danish unless it's included in the price they are already paying for the two interpreters into English. But I really don't see it as a problem, because it works very well, provided that the interpreters have true A and B languages and do not try to work actively into a C language." (DK-EN-DE)

"Each of us should be able to judge whether we feel good enough into our B (able in both meanings, be allowed and be wise enough)" (FR-RU-EN)

"Too many people with weak or average B languages take the risk of working into their B's. There should be more rigorous appraisal of one's level and capacity before attempting it." (EN-FR)

"On the Hungarian market an interpreter cannot afford to work only into A. He or she would not be able to survive. Clients would never accept an interpreter working only into A. Most interpreters $( \pm 70 \%)$ have an A and a strong B language. Few $( \pm 20 \%)$ have A and on B and one C. Even fewer $( \pm 5 \%)$ have A, double B and one C. It is very important to know, which subjects you are not able to do at all. No matter how well you prepare..." (HU-FR/EN-ES)

\section{Category: Pragmatic}

"In international multilingual organizations like European institutions, a

pragmatic approach is followed: preference is given to interpretation into A (from a large number of $\mathrm{C}$ languages), but if for rare languages (ex. East European languages) relevant combinations are not available, European institutions are open to interpretation into B." (FR-DE-EN)

"People should work into B when there is no one who has an A in that B who can work." (ES-EN-FR/IT)

"Not infrequently, especially when doing consecutive, I do not know until the very beginning whether my clients prefer English or Hebrew, sometimes both." (RUHE-EN)

"I am quite pragmatic. I prefer people to work into A, but will work into B if appropriate. It largely depends on the client, i.e. both their perceived needs/standards and the constraints of the team. I might make a disclaimer to the client to make me feel better, 
and they are sometimes very appreciative, but I like them to know I am not best choice. That is part of the overall negotiating context, as the client's resources and perceptions vary." (EN-DE-FR/ES)

"Sometimes there is no alternative...No B-A interpreters available for a certain combination." (EN-ES-FR)

\section{Category: No sweat}

"Even if I feel somewhat more comfortable and can be quicker into my A, I enjoy working into my B, especially with French and English both ways, and it's true that the understanding of my $\mathrm{A}$ is always very precise, whatever the register. Working into $\mathrm{C}$ should be prevented at all costs but into a good and fluent B, why not?" (FREN/ES-CA)

"I really don't feel any difference between A and B. What does make a difference, though, is when for some reason it is necessary to go from B to $\mathrm{C}$ - perhaps because of the different language structure, and because, in my case, of the similarity between Spanish and Portuguese." (PT-EN-ES)

"B language is the formal way of grading. I feel that my A and B languages are, practically, on the same level except that one is my "official" mother tongue and the other is not." (HE-EN)

"I feel quite at home in my B because I live with it daily and my children went to school in it. Sometimes I think my perception of me is worse than my client's, but I know I am more confident into my A, because I can play on more registers." (EN-DEFR/ES)

"For me it is the same as working into A." (IT-EN)

\section{Category: Adamant}

"The quality of the interpretation is always better into A. We generally ask from the speakers to use their mother tongue; if we don't do it, we lose our credibility." (FRDE-EN)

"In Canada, interpreters are expected, for the most part, to be able to work into their B." (FR/EN-PT)

"Into mother tongue should always be favored when possible." (EN-ES-FR/IT)

\section{Category: Miscellaneous}

"The choice of working into B has always to remain mine." (DE-EN-

\section{$\mathrm{RU} / \mathrm{FR} / \mathrm{IT}$ )}

"Although I am originally a French mother-tongue speaker, I did my interpreter 
training in England and trained to work from Spanish and French into English; this might therefore influence my attitude to working into B. Also, I have been living in Britain longer than I have lived in France." (FR-EN)

"Pity I don’t have more opportunities to work into my B language!" (EN-FR-

$\mathrm{DE})$

"I have never understood the categorical arguments against working into B from the Paris School, nor have I ever been fully persuaded by the Russian arguments about the superiority of into B. I think that which is better depends on a lot things, not least how well the B language is really mastered as an active language for the purposes of interpreting *and* the difficulty of understanding the particular speech at hand correctly. My own experience is that sometimes into $\mathrm{A}$ is better and sometimes into $\mathrm{B}$ is better, depending, and a lot of the time there is probably no major difference." (EN-ZH-YUH)

"I have seen more colleagues working from pathetic C's than into less-than perfect B's. A listener can correct the occasional preposition or idiomatic error, however if an interpreter works from a weak $\mathrm{C}$, the meaning he/she does not get is irretrievably lost." (DE-EN).

“My work used to be $100 \%$ into Chinese when I started in 1984, so that's what I am used to; now, with the Chinese taking a more active part, there is also Chinese into German/English, but it is still the lesser part. More and more work is B into B: English into Chinese and vice versa. I don't do German-English, as there are enough other people around." (DE-ZH-EN)

"My B language is near-native and in my case interpretation, consecutive or simultaneous into B does not present any problems. It creates a bit more responsibility since at a big conference English becomes a relay language and you absolutely have to be mindful about your delivery, not too fast, not too slow, distinct and accurate as your colleagues depend on you. In my opinion, this skill has to be emphasized during interpreter training." (RU-EN-FR)

\section{Comparison of First and Second Surveys}

A direct comparison between the first and second surveys is actually next to impossible since the surveys had to be adjusted to be appropriate for the domestic and international markets. Nevertheless since the surveys were conceived with the same intent, it would be of interest to compare the results of the two surveys.

First there are some similarities. Both in Korea, an almost exclusively bilingual market and internationally, the trend is moving towards SI, though the trend is, understandably more pronounced on the international market. There are probably several explanations for this which range from more languages and subsequently, impatience (CI takes a lot of time), better equipment and acceptance/credibility (more people believe that SI is doable). Another similarity was that the majority of the respondents who felt more comfortable working into their mother tongue said that the reason was because they could manipulate their mother tongue better. In addition, those who 
answered that interpretation mode affected whether or not they would work into B, chose not to work in simultaneous mode.

The most visible difference between the two surveys was that not a single respondent in the Korean survey ticked the box "As a matter of principle, interpreters should work only into one's mother tongue." This is understandable since this would negate what dozens of interpreters do on a daily basis on the Korean market.

Regarding the proportion of the direction of their work, the answers of the Korean interpreters were almost a perfect bell curve. The largest proportion $(33 \%)$ answered that the proportion was equally half and half, with 33\% saying that the range was from 80-60\% into English and another $33 \%$ saying that it was from $40-30 \%$. In contrast, only $18 \%$ of the respondents from the AIIC survey said that about half of their work was into B, with the majority of the respondents $(55 \%)$ answering that less than half of their work was into B. This is also a natural correlation because $50 \%$ of the respondents had English as a B language; $20 \%$ French; and $10 \%$ Spanish, meaning that there are probably other interpreters with those languages as an A who could cover that direction.

For the general comments, the Korean respondents were, by far, more reticent than their foreign counterparts. Those who did make some additional comments felt that the interpretation mode or direction did not really matter, but that it was a matter of the subject and degree of knowledge in that subject area. The respondent went further and added that "an interpreter should feel comfortable about working with both languages" (Lim, 2003: 171), indicating that working into $\mathrm{B}$ is not the exception but rather the rule.

\section{Discussion and Conclusion}

The general indication from the first survey (Korea) is that in order to survive in a predominantly bilingual market, it is essential to be able to work in both directions. In contrast, in the second survey, it was found that while most of the respondents tended to work mainly into their A, they nevertheless accepted the fact that interpreting into B was necessary in some situations. Taking these results with the theoretical arguments, the general feeling among AIIC members seems to be that one should preferably work into A, but sometimes there is no choice; it's a fact of life; and as long as it is a strong, quality B, it usually does not do much harm. In Korea, however, it is considered, without question, the norm. For this reason, interpretation in both directions is without exception included in all the curricula of relevant institutions, and there is not questioning or resistance.

Regarding the other directions, there was one interpreter who talked about working from B into B. This was not included in the survey, but it would seem to go against the grain of both the Paris and Russian Schools since it does not have the advantage of working into a flexible mother tongue from a fully understood B language (Paris School) nor does it have the advantage of having fully understood the mother tongue to work into a workable B (Russian school). Working from $\mathrm{B}$ into B would not have either advantage, but both of the weak points, and thus should be discouraged at all costs. A few interpreters also mentioned that they worked into C. The question had been asked simply to cover all bases but with no expectation that any interpreter would answer positively - one interpreter was indignant that I had asked the question.

All in all, the question of directionality can be summarized in a phrase: theoretically, it is recommended to work into one's mother tongue, however, the reality is not always so accommodating. Therefore, care should be taken so that all of the conditions are optimum to ensure the best quality possible when working into B.

\section{NOTES}

1. This definition is actually quite confusing because it sounds as if interpreters could, for example, work from their ' $C$ ' language into their ' $B$ ' language. In addition, in the sentence "Some interpreters [work] into a 
"B" language in only one of the two modes of interpretation" the word 'work' was added because it was missing in the original.

2. This goes without saying. Having taught at the GSIT of HUFS for more than a dozen years, I have found that while most students sooner or later manage to do SI into Korean, their 'A' language, the hurdle lies in working into B. Consequently, most of the students who ultimately become professional freelance interpreters have spent some years abroad and have had schooling in English.

3. At the ASEAN+3, APEC and ASEM summit meetings, there are so many languages which are not official languages on the international stage. Usually the Korean, Chinese and Japanese interpreters at these meetings are conference interpreters, but the Vietnamese, Thai, Cambodian etc. 'interpreters' are public servants who can speak some English. Hardly the ideal situation, even in such cases, there is no choice but to resort to relay interpretation. For meetings that bring together representatives from Korea, China and Japan, the pivot language is usually English. For example, when the Korean representative speaks, the Korean interpreter will interpret that into English and the Chinese and Japanese booths will interpret it back into their relevant languages. If that were not the case, four interpreters per booth would be needed.

4. For the full article refer to Lim, H.O. (2003). Interpreting into B: To B or not to B? FORUM 1-2. pp.151-171.

5. The Korean-English interpretation/translation market is by far the largest and the interpreters and translators with this language combination work the most. Therefore, it was considered that they would be best suited to express their opinions about interpreting into B.

\section{REFERENCES}

AIIC website (a) http://www.aiic.net/glossary/default.cfm?ID=49

(b) http://www.aiic.net/glossary/default.cfm?ID=52

BAKER, M. (1992): In Other Words, London, Routledge.

DeJEAn LeFÉAL, K. (2000): Perfecting Active and Passive Languages, Conference Interpretation and Translation 2 , pp. 7-23.

DOLlerup, C. (1996): The emergence of the teaching of translation, in C. DolleruP and V. APPEL (Eds.), Teaching translation and interpreting 3: New horizons, Amsterdam/Philadelphia: John Benjamins.

Donovan, C. (1998): Teaching Expression in Interpretation, in F. IsRAEL (ed.) Quelle Formation Pour le Traducteur de l'An 2000? Actes du Colloque International tenu a l'ESIT les 6, 7 et 8 juin 1996, Paris, Didier Erudition.

Donovan, C. (2003): Teaching simultaneous interpretation into B, in D. Kelly, A. Martin, M. NobS, D. SANCHEZ, C. WAY (Eds.), La direccionalidad en traduccion e interpretacion [Directionality in translation and interpretation] (pp.367-180), Granada, Editorial Atrio.

LIM, H.O. (2001): Curriculum Design for Schools of Interpretation and Translation, Journal of the Interpretation and Translation Institute 5, pp. 129-153.

LIM, H.O. (2003): Interpreting into B: To B or not to B? FORUM 1-2, pp. 151-171.

MinNs, P. (2002): The teaching of interpreting into B - Some conclusions gathered from 25 years' training experience. Conference Interpretation and Translation 4-2, pp. 29-40.

Newmark, P. (1981): Approaches to Translation, Oxford, New York, Toronto, Sydney, Frankfurt, Pergamon Press.

PÖCHHACKeR, F. (2004): Introducing Interpreting Studies, London and New York, Routledge.

Seleskovitch, D. (1999): The Teaching of Conference Interpretation in the Course of the Last 50 Years, Interpreting 4-1, pp.55-66.

Seleskovitch, D. and M. Lederer (1989): A Systematic Approach to Teaching Interpretation, Luxembourg, Didier Erudition.

SETtON, R. (1994): Experiments in the Application of Discourse Studies to Interpreter Training, in C. DOLLERUP and A. LindeGAARD (Eds.), Teaching translation and interpreting 2: Insights, aims, visions, Amsterdam/Philadelphia, John Benjamins. 
Appendix 1 Survey: Interpretation into B (AIIC members)

1. How long have you been a member of AIIC?

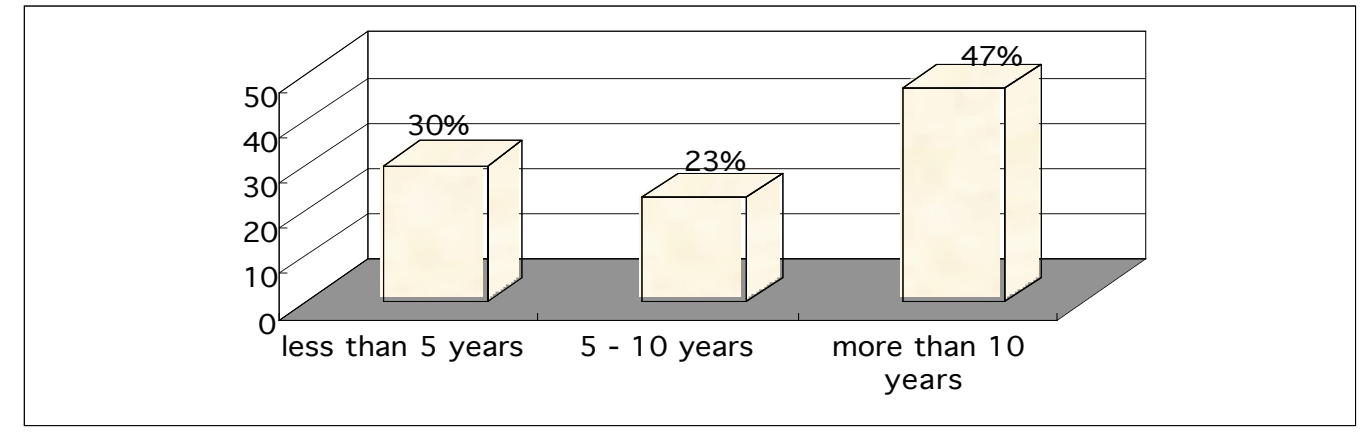

2. What is your language combination?

\begin{tabular}{|l|l|l|}
\hline A language & $\begin{array}{l}\mathrm{n}^{\circ} \text { of } \\
\text { respondents }\end{array}$ & Percentage \\
\hline AR & 1 & $1 \%$ \\
\hline DE & 19 & $24 \%$ \\
\hline DK & 2 & $3 \%$ \\
\hline EN & 14 & $18 \%$ \\
\hline ES & 4 & $5 \%$ \\
\hline FR & 20 & $25 \%$ \\
\hline HE & 1 & $1 \%$ \\
\hline HU & 1 & $1 \%$ \\
\hline IT & 1 & $1 \%$ \\
\hline JA & 2 & $3 \%$ \\
\hline KO & 3 & $4 \%$ \\
\hline PT & 2 & $3 \%$ \\
\hline RU & 6 & $8 \%$ \\
\hline SV & 1 & $1 \%$ \\
\hline TR & 1 & $1 \%$ \\
\hline ZH & 1 & $1 \%$ \\
\hline total & 79 & $100 \%$ \\
\hline
\end{tabular}

\begin{tabular}{|l|l|l|}
\hline B language & $\begin{array}{l}\mathrm{n}^{\circ} \text { of } \\
\text { respondents }\end{array}$ & Percentage \\
\hline CA & 1 & $1 \%$ \\
\hline DE & 7 & $8 \%$ \\
\hline EN & 42 & $50 \%$ \\
\hline ES & 8 & $10 \%$ \\
\hline FR & 17 & $20 \%$ \\
\hline HE & 2 & $2 \%$ \\
\hline IT & 2 & $2 \%$ \\
\hline SV & 1 & $1 \%$ \\
\hline
\end{tabular}




\begin{tabular}{|l|l|l|}
\hline RU & 1 & $1 \%$ \\
\hline PT & 1 & $1 \%$ \\
\hline YUH & 1 & $1 \%$ \\
\hline ZH & 1 & $1 \%$ \\
\hline total & 84 & $100 \%$ \\
\hline
\end{tabular}

\begin{tabular}{|l|l|l|}
\hline C language & $\begin{array}{l}\mathrm{n}^{\circ} \text { of } \\
\text { respondents }\end{array}$ & Percentage \\
\hline CA & 2 & $3 \%$ \\
\hline DE & 6 & $8 \%$ \\
\hline DK & 1 & $1 \%$ \\
\hline EN & 21 & $28 \%$ \\
\hline ES & 10 & $13 \%$ \\
\hline FR & 20 & $26 \%$ \\
\hline IT & 8 & $11 \%$ \\
\hline PT & 4 & $5 \%$ \\
\hline RU & 2 & $3 \%$ \\
\hline SV & 2 & $3 \%$ \\
\hline total & 76 & $100 \%$ \\
\hline
\end{tabular}

3. What percentage of your work is consecutive compared to simultaneous interpretation?
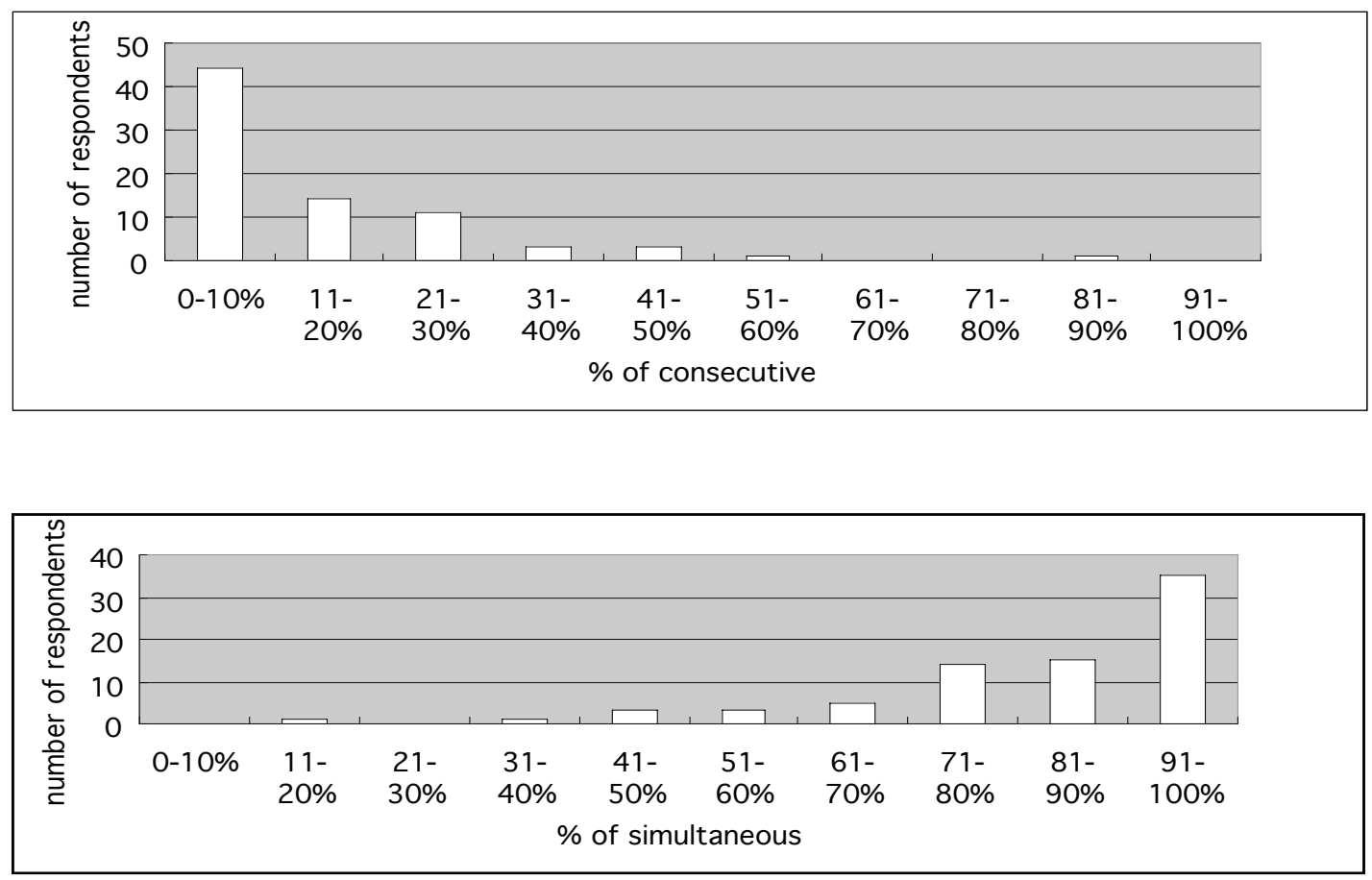
4. What is the proportion of the direction into which you work?
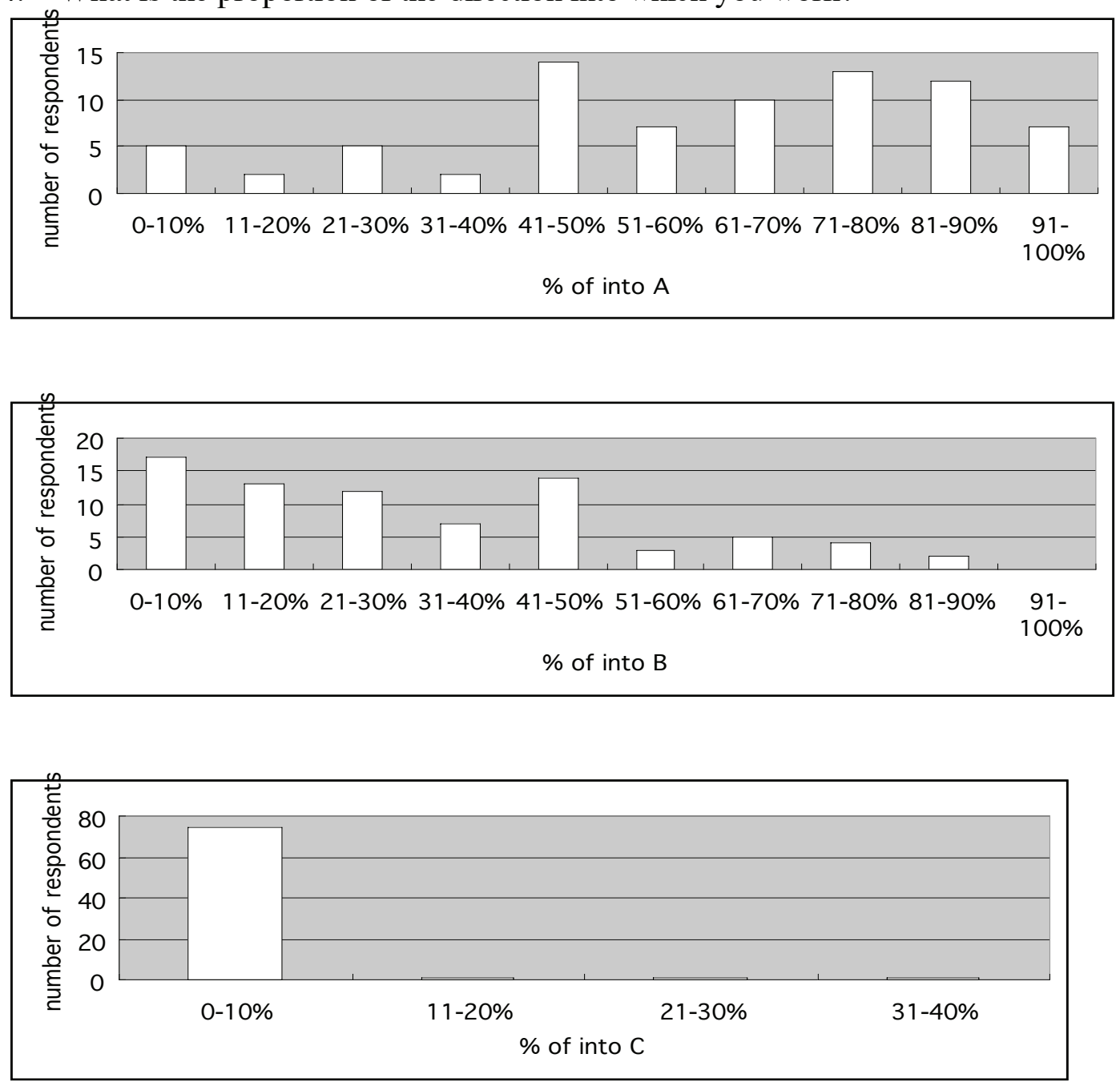

5. Do you feel more comfortable working into A or into B?

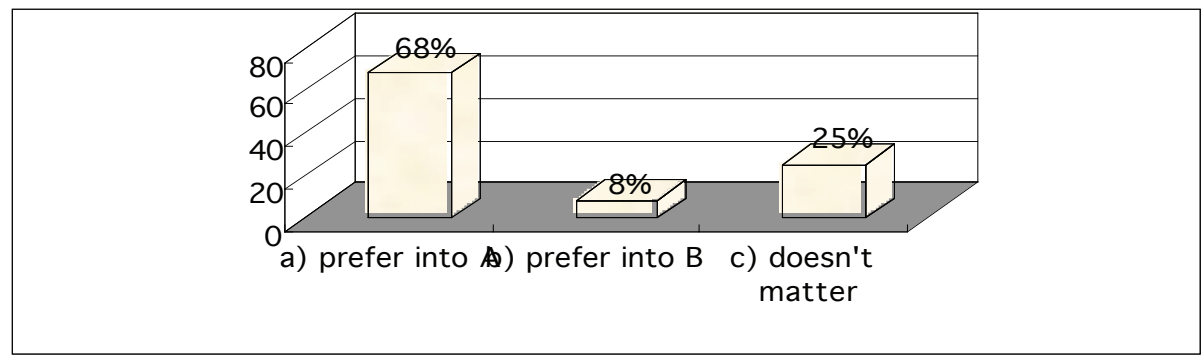


6. If you answered that you feel more comfortable working into B, what is the reason?

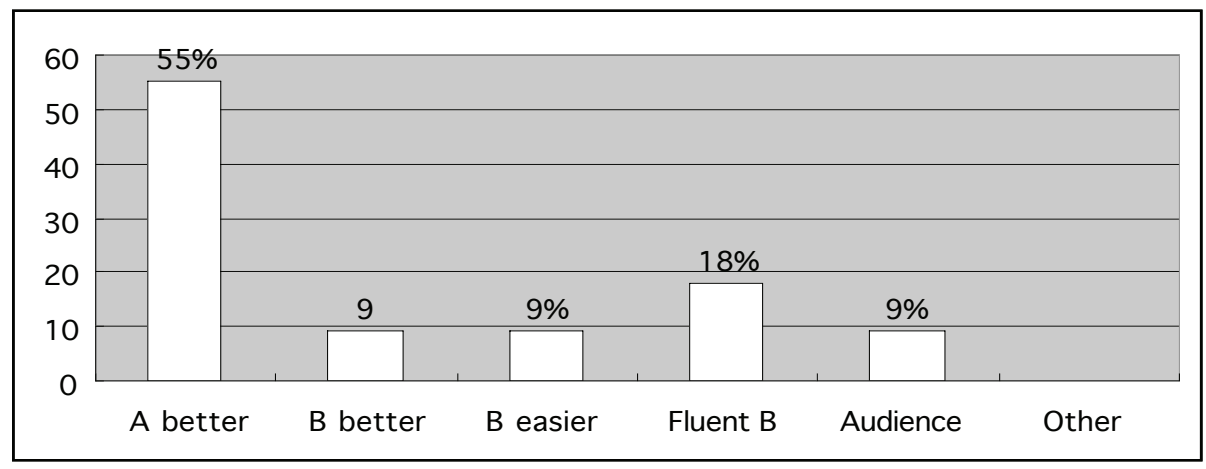

7. If you answered that you feel more confortable working into A, what is the reason?

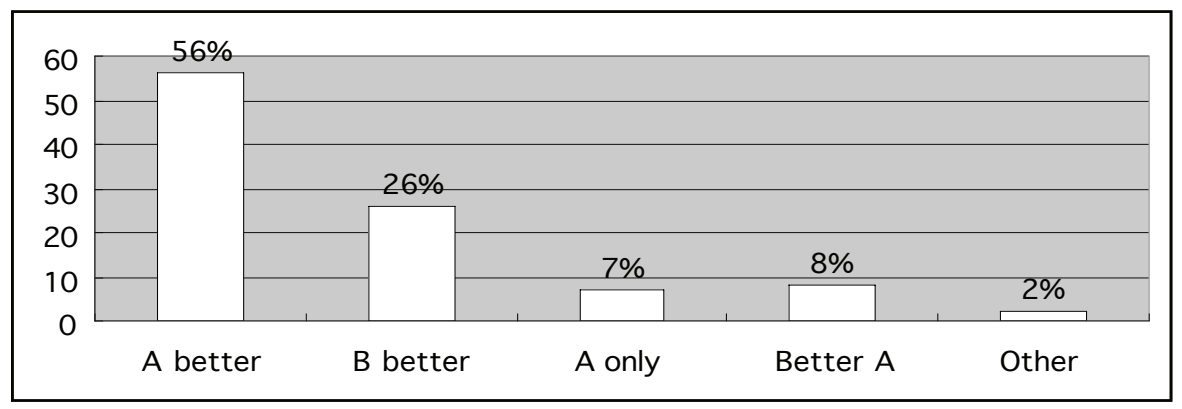

8. Does the interpretation mode (simultaneous or consecutive) affect whether you will work into $\mathrm{B}$ ?

\begin{tabular}{|l|l|l|}
\hline Yes & 19 & $25 \%$ \\
\hline No & 58 & $75 \%$ \\
\hline total & 77 & $100 \%$ \\
\hline
\end{tabular}

8-a. If you answered yes, which of the following modes do you prefer not to work into B?

\begin{tabular}{|l|l|l|}
\hline a) don't prefer consecutive & 3 & $16 \%$ \\
\hline b) don't prefer simultaneous & 16 & $84 \%$ \\
\hline total & 19 & $100 \%$ \\
\hline
\end{tabular}


9. How do you feel in general about working into B? (multiple answers acceptable.)

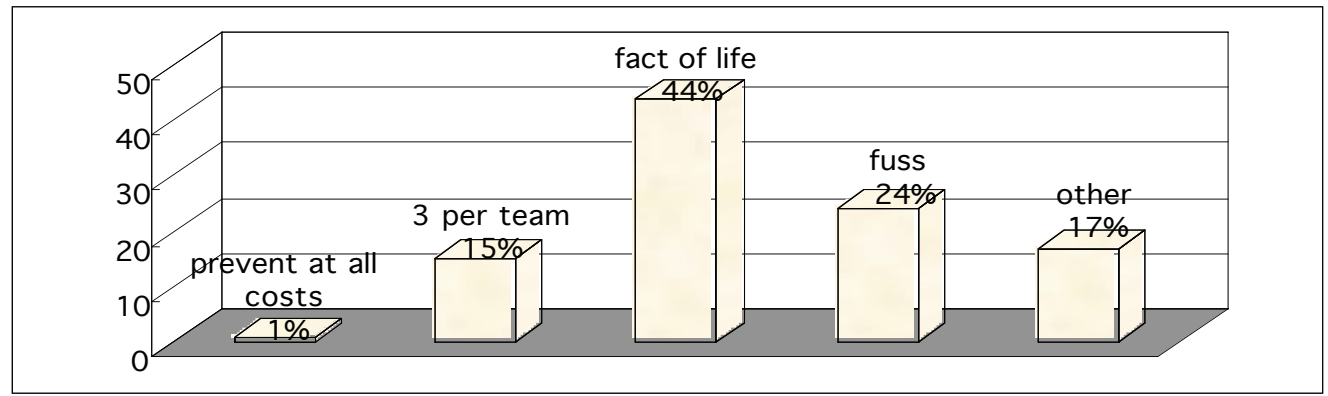

